\title{
Synthesis of the Data on COVID-I9 Skin Manifestations: Underlying Mechanisms and Potential Outcomes
}

\author{
Eleonora Farinazzo' \\ Caterina Dianzani ${ }^{2}$ \\ Iris Zalaudek' \\ Claudio Conforti ${ }^{1}$ \\ Stephan Grabbe ${ }^{3}$ \\ Mohamad Goldust ${ }^{3}$ \\ 'Dermatology Clinic, Maggiore Hospital, \\ University of Trieste, Trieste, Italy; \\ ${ }^{2}$ Dermatology Section, Department of \\ Plastic, Reconstructive and Cosmetic \\ Surgery, Campus Biomedico University \\ Hospital, Rome, Italy; ${ }^{3}$ Department of \\ Dermatology, University Medical Center \\ Mainz, Mainz, Germany
}

\begin{abstract}
The incidence of coronavirus disease 2019 (COVID-19)-related skin manifestations has progressively grown, in parallel with the global severe acute respiratory syndrome coronavirus 2 (SARS-CoV-2) spreading. The available evidence indicates that cutaneous signs are heterogeneous and can be divided as follows: a) erythematous rashes, b) lesions of vascular origin, c) vesicular rashes, d) urticarial rashes, and e) acute generalized exanthematous pustulosis (AGEP), erythema multiforme (EM) and other polymorphic/atypical reactions. Most cutaneous manifestations appear simultaneously or after respiratory and/or systemic symptoms such as fever, even if rarely urticaria has been reported as the first sign of the disease. It has been proposed that erythematous and vesicular rashes, as well as urticaria, are the result of immunological activation against Sars-CoV-2, similarly to other viral exanthems; alternatively, reactivation or co-infection of herpesviruses and drug hypersensitivity represent possible etiologic diagnosis that has to be considered. Regarding lesions of vascular origin, ischemic ones are the result of systemic hypercoagulability established in severe infections, whereas chilblains seem to be linked to the type I-interferon massively produced to halt virus replication. AGEP is triggered by drugs, whereas EM could represent a delayed immune response to the virus or a hypersensitivity reaction to drugs elicited by the inflammatory process built to fight the infection. A further pathogenic hypothesis is that the virus, or its particles detected in the skin (particularly in endothelium and eccrine glands), could be responsible for certain skin reactions, including chilblains and EM. From the available data, it appears that chilblains are correlated with younger age and less severe disease, while ischemic manifestations occur in the elderly with severe infection. In conclusion, larger studies are needed to confirm the suggested pathogenetic mechanisms of COVID-19-related skin reactions and to determine the potential prognostic significance of each one.
\end{abstract}

Keywords: COVID-19, skin rashes, SARS-CoV-2, cutaneous manifestations

\section{Introduction}

Since December 2019, the number of individuals infected by the novel severe acute respiratory syndrome-coronavirus-2 (SARS-CoV-2) increased day after day, and in March 2020, the World Health Organization (WHO) declared the coronavirus disease-19 (COVID-19) a pandemic infection. In the last year, reports of different dermatologic manifestations associated with COVID-19 has progressively grown. Currently, the exact incidence of COVID-19 cutaneous signs is unknown, and the available evidence indicates that they are heterogeneous. According to the
Correspondence: Mohamad Goldust Department of Dermatology, University Medical Center of the Johannes Gutenberg University, Mainz, Germany Tel +49 I786-97-425

$\mathrm{Fax}+49$ 6131-17-6629

Email mgoldust@uni-mainz.de 
Table I Summary of Etiopathogenetic Mechanisms of COVID- I9 Skin Manifestations

\begin{tabular}{|c|c|c|c|}
\hline $\begin{array}{l}\text { Type of Skin } \\
\text { Manifestation }\end{array}$ & Localization & Frequency & Etiopathogenetic Mechanism \\
\hline Maculo-papular rashes & Chest, arms & $\begin{array}{l}\text { Most frequent in } \\
\text { adult patients }\end{array}$ & $\begin{array}{l}\text { Adverse drug reactions; immunological activation against the virus; } \\
\text { Herpesviruses 6-7 reactivation }\end{array}$ \\
\hline Chilblain-like rashes & Feet & $\begin{array}{l}\text { Most frequent in } \\
\text { young patients }\end{array}$ & INF-I mediated inflammatory response \\
\hline $\begin{array}{l}\text { Livedo racemosa, retiform } \\
\text { purpura and acral ischemia }\end{array}$ & $\begin{array}{l}\text { Arms, } \\
\text { buttock }\end{array}$ & $\begin{array}{l}\text { Less frequent, } \\
\text { elderly patients }\end{array}$ & Intravascular thrombosis correlated to COVID-19 severity \\
\hline Vesicular rashes & Trunk, arms & $\begin{array}{l}\text { Frequent in adult } \\
\text { patients }\end{array}$ & Eruption caused by SARS-COV-2; Herpesviridae co-infection \\
\hline Urticaria & Trunk, face & $\begin{array}{l}\text { Frequent in adult } \\
\text { patients }\end{array}$ & Triggered by Covid-19 or by drugs used for the systemic disease \\
\hline AGEP/EM & Trunk & Rare & $\begin{array}{l}\text { AGEP: Drug reaction (hydroxychloroquine) } \\
\text { EM: immune response to SARS-CoV- } 2 \text { or hypersensitivity reaction to drugs } \\
\text { elicited by the cytokines cascade triggered by SARS-CoV- } 2\end{array}$ \\
\hline
\end{tabular}

published cases, they can be divided on the basis of clinical presentation as follows: a) erythematous rashes, b) lesions of vascular origin, c) vesicular rashes, d) urticarial rashes, and e) acute generalized exanthematous pustulosis (AGEP), erythema multiforme (EM) and other polymorphic/atypical reactions.

The pathogenetic mechanisms and the role of SARSCoV-2 are not yet definitively understood, but the aim of this review is to summarize the available data on this topic (Table 1).

\section{Erythematous Rashes}

Erythematous rashes represent the most frequent cutaneous manifestation in patients with COVID-19 and typically occur concurrently, or after the onset of COVID-19 symptoms. ${ }^{1,2}$ In this group, the maculo-papular pattern is the most common, followed by the macular and papulosquamous one. ${ }^{1,3-8}$ In addition, other sub-patterns resembling pityriasis rosea, Grover disease and Symmetrical Drug-Related Intertriginous and Flexural Exanthema (SDRIFE) have been described in some case reports. ${ }^{4,9,10}$

Several hypotheses exist to explain the pathogenetic mechanism of these cutaneous manifestations. ${ }^{11}$ In some cases, skin biopsy is consistent with an adverse reaction to drugs taken during infection. ${ }^{3}$ In particular, Rosell-Diaz et al described a series of 12 patients with an itching papular exanthema and eosinophilia, suggesting a potential role of SARS-CoV-2 infection in inducing drugs hypersensitivity. In fact, the authors properly reported that an intercurrent viral disease can facilitate the onset of an adverse drug reaction, as in the case of ampicillin during EBV infection. ${ }^{3}$ In other cases, a drug reaction was ruled out, as some erythematous rashes and an SDRIFE-like eruption resolved without interruption of the ongoing treatment. 5,10 Furthermore, Freeman et al reported that, on the total number of patients with morbilliform rashes, $37 \%$ received no COVID-19 treatment, $15 \%$ received treatment before morbilliform rashes started, and $48 \%$ received treatment after morbilliform rash onset. ${ }^{2}$ Thus, the available data so far showed that some patients developed skin erythematous eruptions while treating COVID-19 with medications, whereas some other developed them without taking any medication. As an alternative hypothesis to a drug-related pathogenesis, these rash morphologies could be interpreted as the result of an immunological activation against the virus, having similar characteristics to other classical viral exanthems. ${ }^{12}$

Finally, new data are emerging on the direct skin localization of the virus: in some cases, the Sars-CoV-2 spike protein was detected in the sweat glands, through immunohistochemical and immunofluorescence analysis. ${ }^{13}$ Even if the analyzed patients by Liu et al had no clinical dermatological signs, it cannot be ruled out that the localization of the virus or its particles in the skin may be 
responsible for cutaneous manifestations that occur in some individuals.

In the cases of pityriasis rosea or pityriasis rosea-like rashes, ${ }^{9,14}$ a temporal relationship between COVID-19 and the onset of the lesions is reported, but causality has not been proven. Pityriasis rosea could be interpreted as a rare cutaneous manifestation of COVID-19, but more probably, it was due to herpesviruses 6-7 reactivation, perhaps triggered by SARS-CoV-2 infection.

In a Spanish study with a large cohort of patients, ${ }^{1}$ maculo-papular rashes were associated with a more severe COVID-19, with a $2 \%$ mortality in the analyzed sample. In the study of Freeman et al, the rate of hospitalization across the group of vesicular/urticarial/macular erythema and morbilliform rashes was $22-45 \%$, with 3 registered deaths. $^{2}$

\section{Lesions of Vascular Origin}

Lesions of vascular origin can be divided into two principal categories: on the one hand, chilblain-like rashes (also called pernio-like lesions or pseudo-chilblain) and, on the other hand, skin findings underlying variable degrees of ischemia, such as livedo racemosa, retiform purpura and acral ischemia. ${ }^{1,2,15-25}$ It has also been described as other vascular sub-patterns like non-necrotic purpura, livedo reticularis, petechial rashes, porcelain-like macules and dry gangrene. ${ }^{17,26-31}$

Compared to maculo-papular eruptions, chilblain-like rashes appeared later in the course of COVID-19 and lasted longer (mean 12.7 days in duration vs 8.6 days in maculo-papular eruptions). ${ }^{1}$ Chilblain also affected younger people compared to the group of livedo racemosa/retiform purpura/acral ischemia. ${ }^{1}$

In regard to chilblain-like rashes, the outbreak of the lesions occurred in climates without such cold temperatures to justify their occurrence. ${ }^{1,2,16,19,21}$ Hence, they are not primary chilblain but, by a pathogenetic point of view, belong to the category of chilblains related to a systemic disease, as the chilblain lupus erythematosus. The histopathology of pernio-like biopsies supported this argument, showing a vacuolar interface dermatitis, papillary dermal edema, and a superficial and deep dermal lymphocytic infiltrate. $^{2}$ It is well known that Type I-interferon (IFN-I) is crucial for the immunologic response against viruses but also it appears to have a role in the pathogenesis of pernio. $^{32}$ It has been suggested that a strong and precocious INF-I mediated inflammatory response in young people can not only inhibit the virus replication but also produce lesions analogue to chilblain lupus. $^{2}$

Other authors, who have conducted immunohistochemical analyses on biopsies from children and adolescents with chilblains, seem to refute this hypothesis. In their sample of seven patients, they found a cytoplasmic granular positivity for SARS-CoV-2 spike protein in endothelial cells of the upper dermis capillary and postcapillary venules, and also in the epithelial cells of eccrine units. Therefore, they propose a direct role of SARS-CoV-2 in causing endothelial injury, rather than an INF-I mediated vascular inflammation. ${ }^{33}$ However, immunohistochemistry for the detection of SARS-CoV-2 remains restricted and subject to cautious interpretation, so further validation of the results is probably needed. ${ }^{34}$ Other results suggest that vascular endothelium internalizes not the whole virion but the cleaved spike protein via the ACE2 receptor. The clivated spike protein might incite the vasoconstriction and endotheliopathy seen in COVID-19. ${ }^{35}$

In the study of Freeman et al, $16 \%$ of patients with pernio-like lesions were hospitalized, compared to $35 \%$ of all other cutaneous manifestations; in 19\% of cases, the lesions were not associated with other COVID-19 symptoms. ${ }^{2}$ These findings are consistent with other studies, in which chilblains have been associated with less severe diseases. ${ }^{1,21}$

The other group of vascular lesions, which comprises livedo racemosa, retiform purpura and acral ischemia, occurred mostly in elderly patients and was associated with more severe disease. In the study of Freeman et al, all patients with retiform purpura to the limbs and buttocks were hospitalized ( $82 \%$ of them with ARDS). ${ }^{2}$ A $10 \%$ mortality rate was found in patients with livedoid or necrotic lesions. ${ }^{1}$

Both lesions of retiform purpura and fixed acral livedo racemosa, submitted to histopathological examination, showed a thrombogenic vasculopathy in small vessels of the dermis and deposition of $\mathrm{C} 3$ and $\mathrm{C} 5 \mathrm{~b}-\mathrm{C} 9$, indicating activation of the complement pathway. ${ }^{20,22}$ Complementmediated microvascular damage was found in both lung and skin tissue in patients with severe disease and some individuals with retiform purpura had concomitant pulmonary thromboembolism. ${ }^{22,25}$ Therefore, livedo racemosa/retiform purpura/acral ischemia seems to be a sign of the hypercoagulation status and intravascular thrombosis correlated to COVID-19 severity. ${ }^{12}$ In fact, elevated values of coagulation parameters (D-dimer, fibrinogen and/or INR) were found in patients with these types of lesions, in the context of strong COVID-19 
inflammation. $^{20,22,25}$ In this group of ischemic lesions, histology showed the presence of non-inflammatory or pauci-inflammatory thrombi with no other histologic features attributable to pernio. ${ }^{2}$

\section{Vesicular Rashes}

Vesicular rashes have been described during COVID-19 infection. Two patterns of possible presentation have emerged: a diffuse one, with polymorphic lesions (papules, vesicles, pustules) and a localized one, with monomorphic lesions and elective involvement of discrete areas of the trunk. ${ }^{36}$ In most cases, the vesicular rash appeared after the onset of COVID-19 symptoms (with a mean latency time of 14 days) and did not appear related to drugs. ${ }^{36}$

Marzano et al reported a varicella-like papulo-vesicular exanthem in 22 patients, 7 of whom underwent skin biopsy, which demonstrated features compatible with viral infection. ${ }^{37}$ In the study, the possibility of varicella was ruled out on the basis of the clinic and past history of previous varicella. ${ }^{37}$ Herpesvirus-family microarray PCR demonstrated herpes, Epstein-Barr and varicella zoster viruses in the vesicle fluid of three patients with a vesicular rash; ${ }^{38}$ on the contrary, PCR assays for herpesviruses and SARS-CoV-2 on vesicle content resulted in negative in four cases. ${ }^{36}$

The pathogenesis of vesicle formation during COVID19 is not entirely clear. In general, the vesicular rash is more specific to viral diseases than other rashes; however, it remains an open question whether SARS-CoV-2 may be responsible for the lesions, or whether co-infections, such as those by herpesviridae, may be involved.

Some authors have proposed a new pathogenetic hypothesis for vesicular lesions, particularly those with a localized pattern. Infection with SARS-CoV-2 could create a susceptibility to latent viral reactivation (eg from herpes virus) of a previously damaged skin area or, conversely, previously healed lesions of another pathology could contribute to the appearance of SARS-CoV-2 skin manifestations. $^{39}$ The affected area is considered a locus minoris resistentiae or an immunocompromised district, $^{40,41}$ and Sars-CoV-2 can precipitate the onset of pathologic lesions. These mechanisms underlie what has been described as the "Wolf isotopic response", which is now re-proposed as a true variant of Koebner phenomenon (type $\mathrm{V}$, in addition to the 4 types originally indicated by Boyd and Neldner). ${ }^{42-44}$

\section{Urticarial Rashes}

Urticarial rash may be an early sign of SARS-CoV-2 infection, as it has often been described as preceding or concomitant to the development of other typical symptoms of infection, such as fever and cough. ${ }^{45-51}$ However, the onset of urticaria has also been described several weeks after COVID-19 symptoms. ${ }^{2}$ In some of the most numerous case-series, it has been reported urticaria rates of $19 \%$, $16 \%$ and $9 \%$ on the total observed skin reactions. ${ }^{1,2,19}$

In many cases, an allergic drug reaction was ruled out because urticaria improved without discontinuation of the drugs. $^{49,52}$ In other cases, the history was negative for medication intake. ${ }^{51}$ Conversely, it has been described that a vasculitic urticaria, which on histopathological examination, was compatible with an adverse drug reaction. $^{53}$

Acute and chronic urticaria are known to be associated with viral infections, both in adults and children. Therefore, it is conceivable that COVID-19 might trigger urticaria in the same way as other viruses of the respiratory tract. On the other hand, it cannot be excluded that the drugs used in some cases may be responsible for urticarial reactions.

A correlation between urticaria and the severity of COVID-19 has not been established; however, its occurrence appears not to worsen the prognosis, ${ }^{46,47,50,52}$ even if Galvan Casas et al found a more severe disease in the analyzed group presenting urticarial and maculopapular lesions. $^{1}$

\section{Acute Generalized Exanthematous Pustulosis (AGEP), Erythema Multiforme (EM) and Other Polymorphic/Atypical Reactions}

Cases of AGEP have been described in SARS-CoV-2 infected patients treated with hydroxychloroquine, ${ }^{54}$ which was already individuated as a drug frequently associated with AGEP. ${ }^{55} \mathrm{~A}$ variant of the latter, called Generalized Pustular Figurate Exanthema (GPFE), has been observed in patients with COVID-19 taking hydroxychloroquine and has been proposed by some authors as an independent clinical entity. ${ }^{56,57}$ GPFE is described as initially urticarial with the development of non-follicular pustules and later characterized by targetoid and arcuate plaques. $^{56,57}$

Besides AGEP, multiple erythema multiforme-like patterns and one case of Stevens-Johnson syndrome have 
been reported. ${ }^{17,28}$ In the study by Rubio-Muniz et al, 5 of 34 patients were individuated as having targetoid lesions with histopathologic features of erythema multiforme. These lesions were all observed after initiation of drug therapies. EM-like exanthems were described in other 4 patients, 16-24 days after the onset of COVID-19 symptoms. ${ }^{58}$ All were hospitalized and treated with medications (lopinavir/ritonavir, hydroxychloroquine, azithromycin, corticosteroids and/or ceftriaxone). It has been proposed that the cytokine inflammatory cascade triggered by the virus could elicit hypersensitivity reactions to drugs. $^{59}$ On the other hand, it is known that $90 \%$ of EM cases are associated with virus infections and only $10 \%$ with drugs. ${ }^{58}$ Therefore, EM lesions could also represent a potential delayed immune response to the virus. ${ }^{17}$

Two cases of chilblain associated with targetoid lesions compatible with EM have been described, in which the Sars-CoV-2 spike protein was found in endothelium and eccrine gland cells through immunofluorescence technique. This finding, if further confirmed, would demonstrate the direct role of the virus in causing some skin manifestations like chilblain and EM. ${ }^{60}$

Finally, other atypical or polymorphic cutaneous manifestations have been described as atypical erythema nodosum, atypical Sweet syndrome, Kawasaki disease-like presentation, generalized pruritus and polymorphic patterns. $^{61-70}$

\section{Conclusion}

Skin manifestations during COVID-19 are heterogeneous. Often it is not easy to classify the skin eruptions in standardized categories and the authors propose different subdivisions. Most appear with or after the classical symptoms of the disease, like cough and fever. Urticaria have seldom been reported before the onset of other symptoms, proposing it as a possible early indicator of infection. Some skin manifestations affect specific age groups: chilblains are more frequent in younger population, while ischemic manifestations like livedo racemosa, retiform purpura and acral ischemia occur in the advanced ages. Erythematous and vesicular rashes are common to other viral infections, as well as urticaria may be associated with infections. These rash morphologies can be the result of immunological activation against SARS-CoV-2, similarly to other viral exanthems, but a reactivation/co-infection of herpesviruses (vesicular and pityriasis rosea-like rashes) or a hypersensitivity reaction to drugs (erythematous and urticarial rashes) have also to be considered.
On the other hand, lesions of vascular origin seem to be linked more specifically with the pathogenesis of COVID-19: ischemic lesions are related to the state of systemic hypercoagulability and intravascular thrombosis established in severe infections, whereas INF-I massively produced in younger people to eliminate the virus, represents a possible relevant cytokine in the pathogenesis of chilblain. AGEP appears to be triggered by drugs, in particular by hydroxychloroquine, whereas EM could represent a delayed immune response to the virus or a hypersensitivity reaction to drugs elicited by the inflammatory cascade in response to virus invasion.

Finally, reports of the spike protein detection in samples of skin tissue (in particular, at the level of the eccrine glands and endothelial cells) do not exclude the possibility of the direct involvement of the virus or its particles in the pathogenesis of some skin manifestations. It is difficult to attribute a definitive prognostic role to the different manifestations because many data come from case reports or small samples of patients. Studies with larger case-series find that chilblains are correlated with a less severe disease, while ischemic lesions with hospitalized and critically ill patients. Furthermore, vesicular rashes appear to be associated with medium severity and urticarial/maculopapular rashes with more severe COVID-19 disease, although to a lesser extent than ischemic manifestations. A homogeneous categorization of reactions across studies is needed, in order to analyze the results as a whole and compare them with each other. Larger studies will allow to confirm or deny the pathogenetic mechanisms that have emerged, as well as to determine whether the different cutaneous reactions may have a value in terms of patient outcome.

\section{Disclosure}

The authors report no conflicts of interest in this work.

\section{References}

1. Galván Casas C, Catala A, Carretero Hernández G, et al. Classification of the cutaneous manifestations of COVID-19: a rapid prospective nationwide consensus study in Spain with 375 cases. Br J Dermatol. 2020;183(1):71-77. doi:10.1111/bjd.19163

2. Freeman EE, McMahon DE, Lipoff JB, et al. The spectrum of COVID-19-associated dermatologic manifestations: an international registry of 716 patients from 31 countries. J Am Acad Dermatol. 2020;83(4):1118-1129. doi:10.1016/j.jaad.2020.06.1016

3. Rosell-Díaz AM, Mateos-Mayo A, Nieto-Benito LM, et al. Exanthema and eosinophilia in covid-19 patients: has viral infection a role in drug induced exanthemas? J Eur Acad Dermatol Venereol. 2020;34(10): e561-e563. doi:10.1111/jdv.16709

4. Sachdeva M, Gianotti R, Shah M, et al. Cutaneous manifestations of COVID-19: report of three cases and a review of literature. J Dermatol Sci. 2020;98(2):75-81. doi:10.1016/j.jdermsci.2020.04.011 
5. Tamai M, Maekawa A, Goto N, et al. Three cases of COVID-19 patients presenting with erythema. J Dermatol. 2020;47 (10):1175-1178. doi:10.1111/1346-8138.15532

6. Recalcati S. Cutaneous manifestations in COVID-19: a first perspective. J Eur Acad Dermatol Venereol. 2020;34(5):e212-e213.

7. Rivera-Oyola R, Koschitzky M, Printy R, et al. Dermatologic findings in 2 patients with COVID-19. JAAD Case Rep. 2020;6 (6):537-539. doi:10.1016/j.jdcr.2020.04.027

8. Annunziata MC, Patrì A, Ruggiero A, et al. Cutaneous involvement during COVID-19 pandemic: an emerging sign of infection. $J$ Eur Acad Dermatol Venereol. 2020;34(11):e680-e682. doi:10.1111/ jdv.16769

9. Veraldi S, Romagnuolo M, Benzecry V. Pityriasis rosea-like eruption revealing COVID-19. Australas J Dermatol. 2020;62(2):e333-e334.

10. Mahé A, Birckel E, Krieger S, Merklen C, Bottlaender L. A distinctive skin rash associated with coronavirus disease 2019 ? J Eur Acad Dermatol Venereol. 2020;34(6):e246-e247. doi:10.1111/ jdv. 16471

11. Conforti C, Dianzani C, Agozzino M, et al. Cutaneous manifestations in confirmed COVID-19 patients: a systematic review. Biology. 2020;9(12):449.

12. Suchonwanit P, Leerunyakul K, Kositkuljorn C. Cutaneous manifestations in COVID-19: lessons learned from current evidence. $\mathrm{J} \mathrm{Am}$ Acad Dermatol. 2020;83(1):e57-e60. doi:10.1016/j.jaad.2020.04.094

13. Liu J, Li Y, Liu L, et al. Infection of human sweat glands by SARS-CoV-2. Cell Discov. 2020;6(1):1-3. doi:10.1038/s41421-0190132-8

14. Sanchez A, Sohier P, Benghanem S, et al. Digitate papulosquamous eruption associated with severe acute respiratory syndrome coronavirus 2 infection. JAMA Dermatol. 2020;156(7):819-820. doi:10.1001/jamadermatol.2020.1704

15. Locatelli AG, Robustelli Test E, Vezzoli P, et al. Histologic features of long-lasting chilblain-like lesions in a paediatric COVID-19 patient. J Eur Acad Dermatol Venereol. 2020;34(8):e365-e368. doi:10.1111/jdv.16617

16. Piccolo V, Neri I, Filippeschi C, et al. Chilblain-like lesions during COVID-19 epidemic: a preliminary study on 63 patients. $J$ Eur Acad Dermatol Venereol. 2020;34(7):e291-e293. doi:10.1111/jdv.16526

17. Rubio-Muniz CA, Puerta-Peña M, Falkenhain-López D, et al. The broad spectrum of dermatological manifestations in COVID-19: clinical and histopathological features learned from a series of 34 cases. J Eur Acad Dermatol Venereol. 2020;34(10):e574-e576. doi:10.1111/ jdv. 16734

18. Andina D, Noguera-Morel L, Bascuas-Arribas M, et al. Chilblains in children in the setting of COVID-19 pandemic. Pediatr Dermatol. 2020;37(3):406-411. doi:10.1111/pde.14215

19. de Masson A, Bouaziz J-D, Sulimovic L, et al. Chilblains is a common cutaneous finding during the COVID-19 pandemic: a retrospective nationwide study from France. $J$ Am Acad Dermatol. 2020;83(2):667-670. doi:10.1016/j.jaad.2020.04.161

20. Droesch C, Do MH, DeSancho M, Lee E-J, Magro C, Harp J. Livedoid and purpuric skin eruptions associated with coagulopathy in severe COVID-19. JAMA Dermatol. 2020;156(9):1-3. doi:10.1001/jamadermatol.2020.2800

21. Freeman EE, McMahon DE, Lipoff JB, et al. Pernio-like skin lesions associated with COVID-19: a case series of 318 patients from 8 countries. J Am Acad Dermatol. 2020;83(2):486-492. doi:10.1016/j. jaad.2020.05.109

22. Bosch-Amate X, Giavedoni P, Podlipnik S, et al. Retiform purpura as a dermatological sign of coronavirus disease 2019 (COVID-19) coagulopathy. J Eur Acad Dermatol Venereol. 2020;34(10):e548-e549. doi:10.1111/jdv.16689

23. Kolivras A, Dehavay F, Delplace D, et al. Coronavirus (COVID-19) infection-induced chilblains: a case report with histopathologic findings. JAAD Case Rep. 2020;6(6):489-492. doi:10.1016/j. jdcr.2020.04.011
24. Landa N, Mendieta-Eckert M, Fonda-Pascual P, Aguirre T. Chilblainlike lesions on feet and hands during the COVID-19 pandemic. Int J Dermatol. 2020;59(6):739. doi:10.1111/ijd.14937

25. Magro C, Mulvey JJ, Berlin D, et al. Complement associated microvascular injury and thrombosis in the pathogenesis of severe COVID-19 infection: a report of five cases. Transl Res. 2020;220:1-13. doi:10.1016/j.trsl.2020.04.007

26. Bouaziz JD, Duong TA, Jachiet M, et al. Vascular skin symptoms in COVID-19: a French observational study. $J$ Eur Acad Dermatol Venereol. 2020;34(9):e451-e452. doi:10.1111/jdv.16544

27. Conforti C, Zalaudek I, Giuffrida R, et al. "COVID-mask": an atypical livedoid manifestation of COVID-19 observed in a northern Italy hospital. Dermatol Ther. 2020;33(4):e13701. doi:10.1111/ dth. 13701

28. Chaabane I, Loukil M, Amri R, et al. Cutaneous manifestations of COVID-19: report of three cases. Arch Dermatol Res. $2020 ; 1-4$.

29. Diaz-Guimaraens B, Dominguez-Santas M, Suarez-Valle A, et al. Petechial skin rash associated with severe acute respiratory syndrome coronavirus 2 infection. JAMA Dermatol. 2020;156(7):820-822. doi:10.1001/jamadermatol.2020.1741

30. Dominguez-Santas M, Diaz-Guimaraens B, Garcia Abellas P, Moreno-Garcia Del Real C, Burgos-Blasco P, Suarez-Valle A. Cutaneous small-vessel vasculitis associated with novel 2019 coronavirus SARS-CoV-2 infection (COVID-19). J Eur Acad Dermatol Venereol. 2020;34(10):e536-e537. doi:10.1111/jdv.16663

31. Manalo IF, Smith MK, Cheeley J, Jacobs R. A dermatologic manifestation of COVID-19: transient livedo reticularis. $J$ Am Acad Dermatol. 2020;83(2):700. doi:10.1016/j.jaad.2020.04.018

32. Battesti G, El Khalifa J, Abdelhedi N, et al. New insights in COVID19-associated chilblains: a comparative study with chilblain lupus erythematosus. J Am Acad Dermatol. 2020;83(4):1219-1222. doi:10.1016/j.jaad.2020.06.1018

33. Colmenero I, Santonja C, Alonso-Riaño M, et al. SARS-CoV-2 endothelial infection causes COVID-19 chilblains: histopathological, immunohistochemical and ultrastructural study of seven paediatric cases. Br J Dermatol. 2020;183(4):729-737. doi:10.1111/ bjd. 19327

34. Baeck M, Hoton D, Marot L, Herman A. Chilblains and COVID-19: why SARS-CoV-2 endothelial infection is questioned. Br J Dermatol. 2020;183(6):1152-1153. doi:10.1111/bjd.19489

35. Ko CJ, Harigopal M, Gehlhausen JR, Bosenberg M, McNiff JM, Damsky W. Discordant anti-SARS-CoV-2 spike protein and RNA staining in cutaneous perniotic lesions suggests endothelial deposition of cleaved spike protein. J Cutan Pathol. 2021;48(1):47-52. doi:10.1111/cup.13866

36. Fernandez-Nieto D, Ortega-Quijano D, Jimenez-Cauhe J, et al. Clinical and histological characterization of vesicular COVID-19 rashes: a prospective study in a tertiary care hospital. Clin Exp Dermatol. 2020;45(7):872-875. doi:10.1111/ced.14277

37. Marzano AV, Genovese G, Fabbrocini G, et al. Varicella-like exanthem as a specific COVID-19-associated skin manifestation: multicenter case series of 22 patients. J Am Acad Dermatol. 2020;83(1):280-285. doi:10.1016/j.jaad.2020.04.044

38. Llamas-Velasco M, Rodríguez-Jiménez P, Chicharro P, De Argila D, Muñoz-Hernández P, Daudén E. Reply to "varicella-like exanthem as a specific COVID-19-associated skin manifestation: multicenter case series of 22 patients": to consider varicella-like exanthem associated with COVID-19, virus varicella zoster and virus herpes simplex must be ruled ou. J Am Acad Dermatol. 2020;83(3):e253-e254. doi:10.1016/j.jaad.2020.04.180

39. Tatu AL, Baroiu L, Fotea S, et al. A working hypothesis on vesicular lesions related to COVID-19 infection, Koebner Phenomena Type V, and a short review of related data. Clin Cosmet Investig Dermatol. 2021;14:419-423. doi:10.2147/CCID.S307846 
40. Ruocco V, Ruocco E, Piccolo V, Brunetti G, Guerrera LP, Wolf R. The immunocompromised district in dermatology: a unifying pathogenic view of the regional immune dysregulation. Clin Dermatol. 2014;32(5):569-576. doi:10.1016/j.clindermatol.2014.04.004

41. Caccavale S, Kannangara AP, Ruocco E. Categorization of and comments on isomorphic and isotopic skin reactions. Clin Dermatol. 2017;35(1):105-110. doi:10.1016/j.clindermatol.2015.10.011

42. Happle R, Kluger N. Koebner's sheep in wolf's clothing: does the isotopic response exist as a distinct phenomenon? J Eur Acad Dermatol Venereol. 2018;32(4):542-543. doi:10.1111/jdv.14664

43. Nwabudike LC, Tatu AL. Reply to Happle R. et al. Koebner's sheep in wolf's clothing: does the isotopic response exists as a distinct phenomenon? J Eur Acad Dermatol Venereol. 2018;32(8):e336e337. doi: $10.1111 / j d v \cdot 14900$

44. Boyd AS, Neldner KH. The isomorphic response of Koebner. Int J Dermatol. 1990;29(6):401-410. doi:10.1111/j.1365-4362.1990. tb03821.x

45. Najafzadeh M, Shahzad F, Ghaderi N, Ansari K, Jacob B, Wright A. Urticaria (angioedema) and COVID-19 infection. J Eur Acad Dermatol Venereol. 2020;34(10):e568-e570. doi:10.1111/jdv.16721

46. Quintana-Castanedo L, Feito-Rodríguez M, Valero-López I, Chiloeches-Fernández C, Sendagorta-Cudós E, Herranz-Pinto P. Urticarial exanthem as early diagnostic clue for COVID-19 infection. JAAD Case Rep. 2020;6(6):498-499. doi:10.1016/j.jdcr.2020.04.026

47. Henry D, Ackerman M, Sancelme E, Finon A, Esteve E. Urticarial eruption in COVID-19 infection. $J$ Eur Acad Dermatol Venereol. 2020;34(6):e244-e245. doi:10.1111/jdv.16472

48. Ahouach B, Harent S, Ullmer A, et al. Cutaneous lesions in a patient with COVID-19: are they related? Br J Dermatol. 2020;183(2):e31e31. doi:10.1111/bjd.19168

49. Falkenhain-López D, Sánchez-Velázquez A, López-Valle A, OrtizFrutos FJ. SARS-coronavirus-2 and acute urticaria. Int J Dermatol. 2020;59(7):867-868. doi:10.1111/ijd.14950

50. Van Damme C, Berlingin E, Saussez S, Accaputo O. Acute urticaria with pyrexia as the first manifestations of a COVID-19 infection. J Eur Acad Dermatol Venereol. 2020;34(7):e300-e301.

51. Hassan K. Urticaria and angioedema as a prodromal cutaneous manifestation of SARS-CoV-2 (COVID-19) infection. BMJ Case Rep. 2020;13(7):e236981. doi:10.1136/bcr-2020-236981

52. Gunawan C, Angela A, Widysanto A. Urticarial eruption in coronavirus disease 2019 infection: a case report in Tangerang, Indonesia. J Eur Acad Dermatol Venereol. 2020;34(8):e372-e373. doi:10.1111/jdv.16622

53. Skroza N, Bernardini N, Balduzzi V, et al. A late onset widespread skin rash in a previous covid-19 infected patient: viral or multidrug effect? J Eur Acad Dermatol Venereol. 2020;34(9):e438-e439. doi: $10.1111 /$ jdv. 16633

54. Robustelli Test E, Vezzoli P, Carugno A, et al. Acute generalized exanthematous pustulosis with erythema multiforme-like lesions induced by hydroxychloroquine in a woman with coronavirus disease 2019 (COVID-19). J Eur Acad Dermatol Venereol. 2020;34(9):e457e459. doi:10.1111/jdv.16613

55. Sidoroff A, Dunant A, Viboud C, et al. Risk factors for acute generalized exanthematous pustulosis (AGEP) - results of a multinational case-control study (EuroSCAR). Br $\quad J$ Dermatol. 2007;157 (5):989-996. doi:10.1111/j.1365-2133.2007.08156.x

Clinical, Cosmetic and Investigational Dermatology

\section{Publish your work in this journal}

Clinical, Cosmetic and Investigational Dermatology is an international, peer-reviewed, open access, online journal that focuses on the latest clinical and experimental research in all aspects of skin disease and cosmetic interventions. This journal is indexed on CAS
56. Schwartz RA, Janniger CK. Generalized pustular figurate erythema: a newly delineated severe cutaneous drug reaction linked with hydroxychloroquine. Dermatol Ther. 2020;33(3):e13380. doi: $10.1111 /$ dth. 13380

57. Abadías-Granado I, Palma-Ruiz AM, Cerro PA, et al. Generalized pustular figurate erythema first report in two COVID-19 patients on hydroxychloroquine. J Eur Acad Dermatol Venereol. 2021;35(1):e5e7. doi:10.1111/jdv.16903

58. Jimenez-Cauhe J, Ortega-Quijano D, Carretero-Barrio I, et al. Erythema multiforme-like eruption in patients with COVID-19 infection: clinical and histological findings. Clin Exp Dermatol. 2020;45 (7):892-895. doi:10.1111/ced.14281

59. Sakaida T, Isao T, Matsubara A, Nakamura M, Morita A. Unique skin manifestations of COVID-19: is drug eruption specific to COVID-19? J Dermatol Sci. 2020;99(1):62-64. doi:10.1016/j. jdermsci.2020.05.002

60. Torrelo A, Andina D, Santonja C, et al. Erythema multiforme-like lesions in children and COVID-19. Pediatr Dermatol. 2020;37 (3):442-446. doi:10.1111/pde.14246

61. Sipfle N, Bridwell RE, Roper J. Erythema nodosum-like rash in a COVID-19 patient: a case report. Am J Emerg Med. 2021;40:227-e1. doi:10.1016/j.ajem.2020.07.063

62. Suter P, Mooser B, Thien HPPH. Erythema nodosum as a cutaneous manifestation of COVID-19 infection. BMJ Case Rep. 2020;13(7): e236613. doi:10.1136/bcr-2020-236613

63. Taşkın B, Vural S, Altuğ E, et al. Coronavirus 19 presenting with atypical sweet's syndrome. J Eur Acad Dermatol Venereol. 2020;34 (10):e534-e535. doi:10.1111/jdv.16662

64. Jones VG, Mills M, Suarez D, et al. COVID-19 and Kawasaki disease: novel virus and novel case. Hosp Pediatr. 2020;10 (6):537-540. doi:10.1542/hpeds.2020-0123

65. Riphagen S, Gomez X, Gonzalez-Martinez C, Wilkinson N, Theocharis P. Hyperinflammatory shock in children during COVID-19 pandemic. Lancet. 2020;395(10237):1607-1608. doi:10.1016/S0140-6736(20)31094-1

66. Spencer R, Closson RC, Gorelik M, et al. COVID-19 inflammatory syndrome with clinical features resembling Kawasaki disease. Pediatrics. 2020;146(3):e20201845. doi:10.1542/peds.2020-1845

67. Aghazadeh N, Homayouni M, Sartori-Valinotti JC. Oral vesicles and acral erythema: report of a cutaneous manifestation of COVID-19. Int J Dermatol. 2020;59(9):1153-1154. doi:10.1111/ijd.15047

68. Klimach A, Evans J, Stevens J, Creasey N. Rash as a presenting complaint in a child with COVID-19. Pediatr Dermatol. 2020;37 (5):966-967. doi:10.1111/pde.14257

69. Wolfe DM, Nassar GN, Divya K, Krilov LR, Noor A. Young children presenting with fever and rash in the midst of SARS-CoV-2 outbreak in New York. Clin Pediatr (Phila). 2020;59(12):1112-1118. doi:10.1177/0009922820941631

70. Dalal A, Jakhar D, Agarwal V, Beniwal R. Dermatological findings in SARS-CoV-2 positive patients: an observational study from North India. Dermatol Ther. 2020;33(6):e13849. doi:10.1111/dth.13849
The manuscript management system is completely online and includes a very quick and fair peer-review system, which is all easy to use. Visit http://www.dovepress.com/testimonials.php to read real quotes from published authors. 